\title{
THE INFLUENCE OF SECOND LANGUAGE TEACHING ON UNDERGRADUATE MATHEMATICS PERFORMANCE
}

\author{
by \\ Ans Gerber \\ Submitted in partial fulfilment of the requirements for the degree of \\ Master of Science: Mathematics Education \\ in the Faculty of Natural and Agricultural Sciences \\ at the \\ University of Pretoria
}

Supervisor: Prof JC Engelbrecht

Co-supervisor: Dr AF Harding

May 2004 
University of Pretoria etd - Gerber, A (2005)

To God be the glory 


\section{ABSTRACT}

Understanding abstract concepts and ideas in mathematics if instruction takes place in the first language of the student is challenging as it is. Yet worldwide students often have to master mathematics via a second or even a third language and this is a recognised problem. The majority of students in South Africa - a country with eleven official languages - have to face this difficulty.

What is the extent of the linguistic disadvantage (if any) of South African second language students?

With the language challenges that South Africa faces today with respect to education as a backdrop, I report on a quantitative investigation into this problem specifically for the case of tertiary mathematics students, focussing on Afrikaans first language learners.

The performance of Afrikaans first language students who attend Afrikaans lectures is compared to that of the Afrikaans first language students who attend English lectures. In a further investigation I explore the influence that second language instruction has on students from African cultures. All the students study at the University of Pretoria.

The study shows that in the comparison of the average performances of the two Afrikaans first language groups, there is no significant difference in the first year university calculus performances, but at secondary school level the Afrikaans students who attend English lectures at university level achieve better results.

When the means are adjusted by removing the influence of school mathematics achievement, the adjusted average performance of the Afrikaans group that attend English lectures differ significantly from that of the Afrikaans group that attend Afrikaans lectures. As a result both of the analyses suggest that, based on mathematics achievement, Afrikaans students who attend English lectures may be at a disadvantage to Afrikaans students attending English lectures do.

The study also indicates that the African students' performances do not differ significantly from that of the Afrikaans students who attend English lectures (both of these groups attend second language lectures).

In the comparison of the pooled groups of first language learners and second language 
University of Pretoria etd - Gerber, A (2005)

learners, there does not seem to be any significant difference between the adjusted mean performances of these groups.

There seems to be no mathematical idea of any importance or profundity that is not mirrored, with an almost uncanny accuracy, in the common use of words.

George Spencer Brown 


\section{CONTENTS}

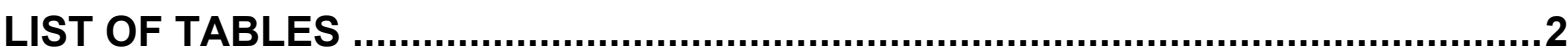

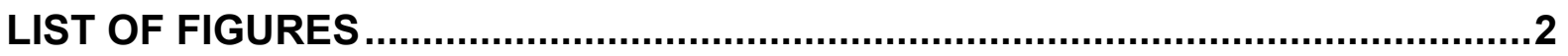

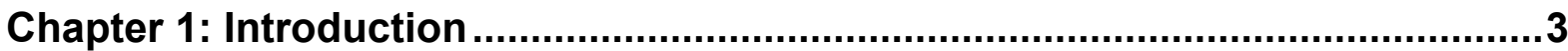

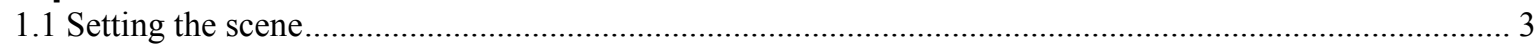

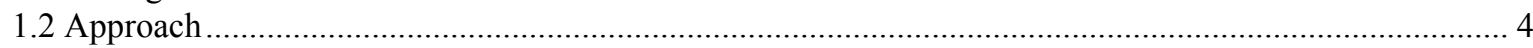

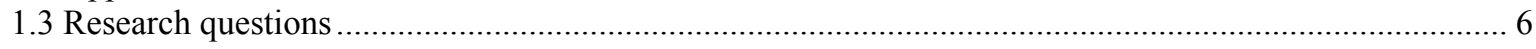

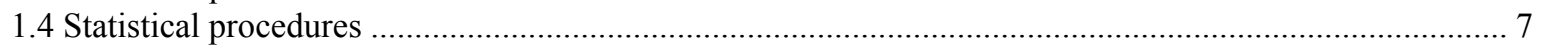

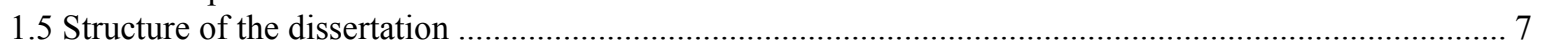

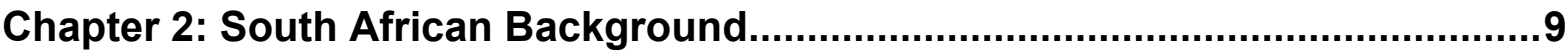

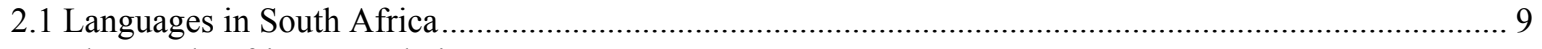

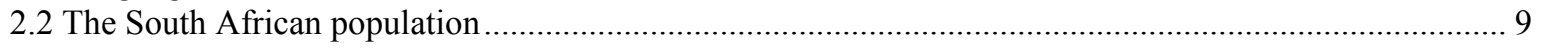

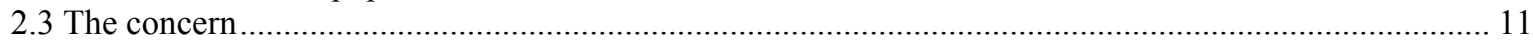

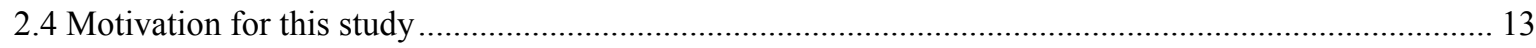

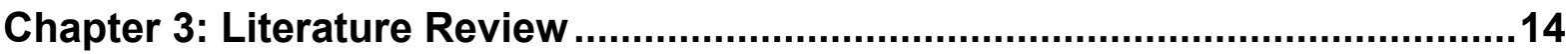

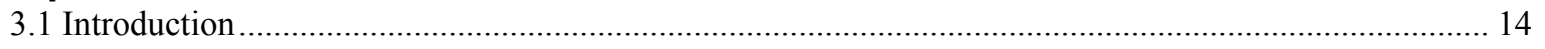

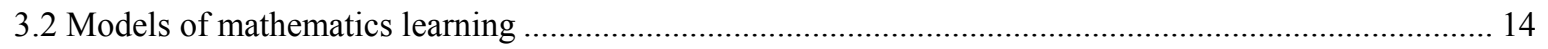

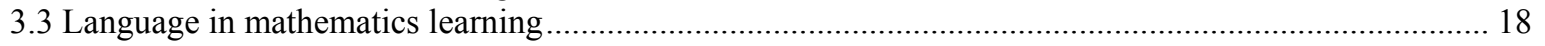

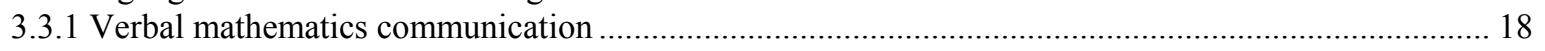

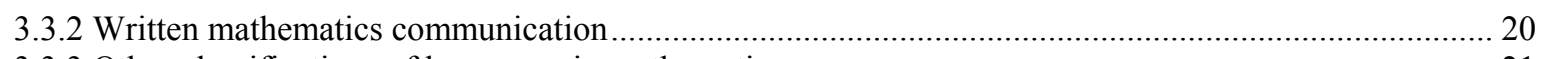

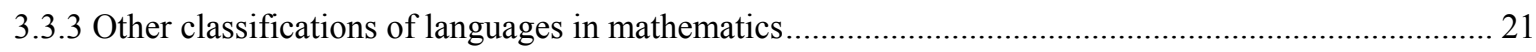

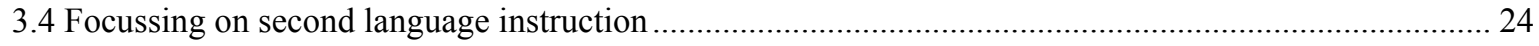

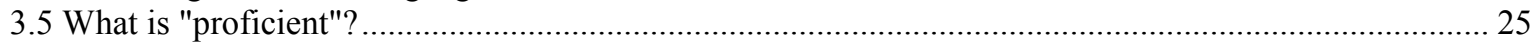

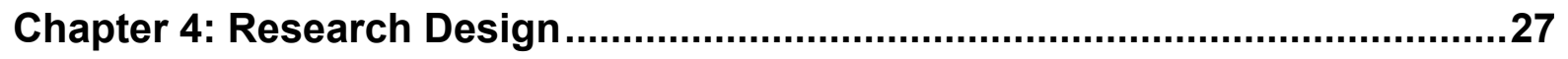

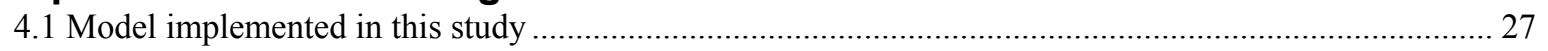

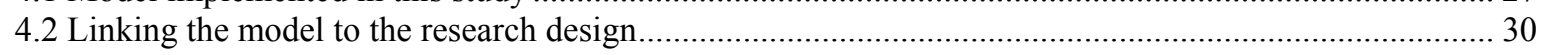

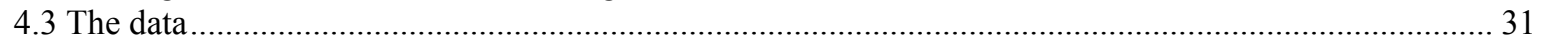

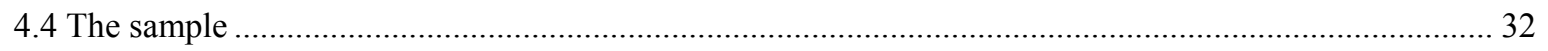

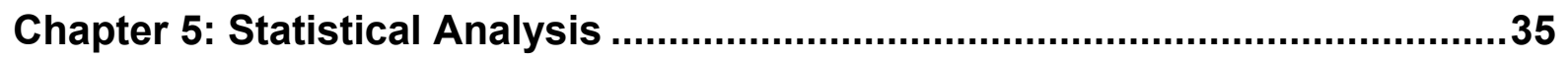

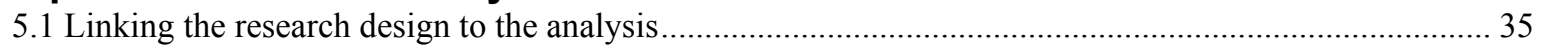

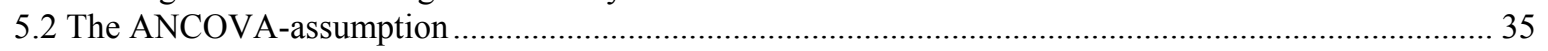

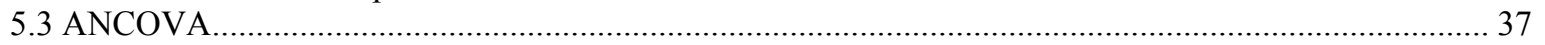

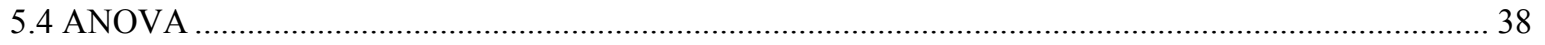

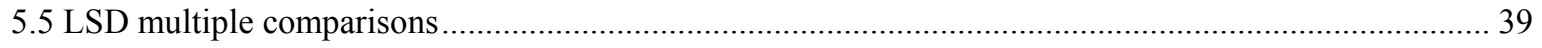

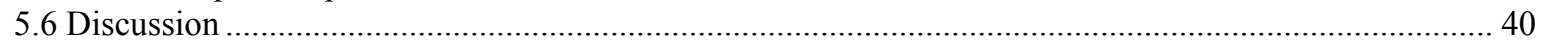

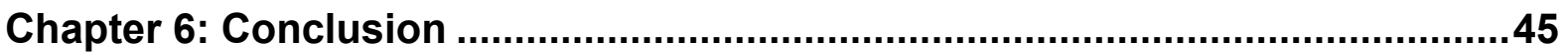

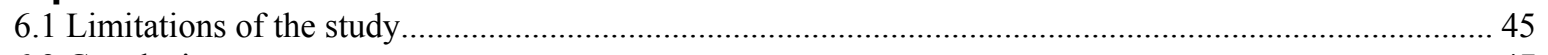

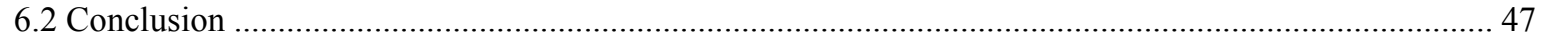

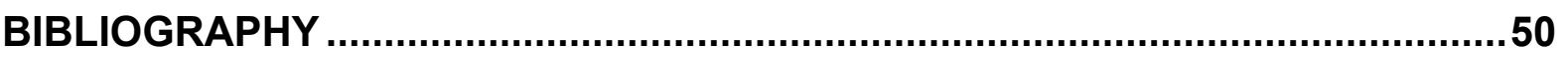




\section{LIST OF TABLES}

TABLE 1: SOUTH AFRICA: HOME LANGUAGE DISTRIBUTION (2001) 10

TABLE 2: STUDENT NUMBERS OF THE UNIVERSITY OF PRETORIA 11

TABLE 3: ABBREVIATIONS FOR SAMPLE GROUPS 32

TABLE 4: GROUP SIZES

TABLE 5: GROUPS THAT CONSTITUTE $\mathrm{B}_{2}$

TABLE 6: REGRESSION COEFFICIENTS (UNIVERSITY CALCULUS VS. GRADE

TWELVE MATHEMATICS) 35

TABLE 7: P-VALUES FOR HYPOTHESIS TESTS FOR SIGNIFICANT

CORRELATION 35

TABLE 8: P-VALUES FOR HYPOTHESIS TESTS FOR EQUAL REGRESSION COEFFICIENTS 36

TABLE 9: OBSERVED AND ADJUSTED MEANS AND P-VALURS IN ANCOVA ANALYSIS

TABLE 10: OBSERVED MEANS AND P-VALUES FOR ANOVA 38

TABLE 11: P-VALUES FOR LSD 39

\section{LIST OF FIGURES}

FIGURE 1: MODEL IMPLEMENTED IN THIS STUDY 


\section{CHAPTER 1}

\section{Introduction}

\subsection{Setting the scene}

In South Africa, a country where less than ten per cent of the population are first language speakers of English, the language most commonly used in public and the media, second language teaching is at the order of the day. When adding to this the fact that the home language of the other ninety per cent of the population can be any one of the other ten official languages or even some other international language, you are faced with one of the most unique educational challenges in the world.

In 1994 South Africa's newly found democracy opened the gateway for students from the black community to embark more freely on tertiary studies. As a result, many of the universities with Afrikaans as teaching medium had to adjust their language policies to accommodate these students by introducing English lectures and tutorials. The change in the political situation also made South African tertiary studies more accessible to international students, who also benefit from increased usage of English in tertiary education.

Although the majority of South African students are exposed to English second language tuition from their secondary education years onwards, there is one group of students that is now being exposed to English second language teaching for the first time only at tertiary level, and increasingly so. This is the group of Afrikaans first language students. The majority of these students have Afrikaans first language instruction for their entire twelve year school career. Once they get to university these students sometimes have to attend English lectures for the first time.

At the University of Pretoria the majority of first year university calculus students are free to attend either Afrikaans or English medium lectures since student numbers permit for parallel lecture sessions to be presented. From the second year level on, however, a greater number of Afrikaans first language students have to attend English lectures, since student numbers do not always warrant parallel sessions. Afrikaans lectures are phased out even 
more at third year level and at graduate level no mathematics course is presented in

Afrikaans. Presenting only English lectures from the first year of tertiary study is gradually becoming a more attractive option since the percentage of Afrikaans first language students has decreased over the last ten or so years and the trend is expected to continue.

There is a big concern in the Afrikaans speaking community that this sudden change in teaching medium from Afrikaans first language school education to English second language tertiary education will impact negatively on student achievement.

At all levels of education, mathematics is often considered to be one of the more difficult subjects. Mathematics is understandably one of the subjects mentioned first when problems concerning second language education are considered. This is mostly because of the fact that the natural sciences - and mathematics in particular - have a particular way of using a language (e.g. English) for scientific discourse. Thus even English first language speakers have to familiarise themselves with a new scientific language, even though it is still English. Having to learn mathematics in a second language then requires of the student to become skilled at two new languages: ordinary English and mathematical English.

In this study I investigate the extent to which Afrikaans first year students' university calculus performances are influenced by a change in teaching medium and whether they perform any different from other second language students. I do this by quantitatively assessing the performances of students from various language backgrounds.

\subsection{Approach}

In order to study the influence of second language instruction on student performance, one has to isolate the linguistic factor from the data. From the literature review it becomes evident that there are many factors that influence student achievement and that it can be difficult to quantitatively isolate the specific influence that language has.

Two main groups of first year calculus students are compared. For one group tuition takes place in the students' home language (Afrikaans or English); for the second group, tuition is in English, a second or third language. The home language of students in the second main group is mostly Afrikaans or one of the African languages.

Two observed variables are analysed: Grade twelve mathematics performance and first 
year university calculus performance. Various statistical techniques are implemented to compare the adjusted means and observed means of these sample groups.

I now give a brief overview of the reasoning followed in locating the role of language in mathematics learning and specifically in investigating the influence of second language instruction on students' academic achievement. A more detailed discussion is given in the literature review. In chapter 4 I give a discussion of a model of reasoning on the role of language in the learning of mathematics and use this reasoning to justify the statistical methods of data analysis that are used.

Mastering mathematics is sometimes considered to be a two-step process: Firstly, the student has to understand the mathematical concepts (Richards, 1982; Thurston, 1995) as verbally explained to him/her by a lecturer. Secondly, the student has to be able to communicate these concepts in written format (Brown, 1994) either by reading or writing mathematics.

In the first step, the lecturer clarifies concepts by using two verbal languages: A commonly spoken, everyday language and a subject-specific, scientific language. Although both of these languages can be embedded in the same language (e.g. English), competency in the former does not necessarily imply competency in the latter (Lemke, 1990). It is of crucial importance that a student is proficient in both, since underlying mathematical concepts is often first conveyed and clarified using spoken explanations.

In the second step students have to familiarise themselves with the scientific manner of communicating acquired concepts in writing. This step is especially important if one considers that this mode of communication also helps the student in acquiring in-depth understanding of abstract concepts since it gives yet another explanation of mathematical concepts. The student needs to be able to read and write mathematics to use textbooks and to be able to complete various assessment activities during a mathematics course. This written mathematics comprises of various forms of communication e.g. purely textual, diagrammatical or symbolic.

The two-step process described above is a simplified approach to mathematics learning and it is important to keep in mind that there are various other influences (e.g. emotional support, learning opportunities, personality traits of the student etc.) that affect a student's 
mathematics achievement. Still, I use this simplified model as a point of departure in this study, i.e. that successful completion of a mathematics course relies heavily on two aspects of language:

- Effective verbal communication of abstract concepts.

- The student's ability to understand and communicate the concepts when translated into written mathematics.

\subsection{Research questions}

This study is the first phase in exploring the influence of second language teaching on the heterogeneous population of first year university calculus students in South Africa. The primary research question is:

What is the extent of the linguistic disadvantage (if any) of South African second language students?

I investigate the hypothesis that Afrikaans first language students have sufficient understanding of English to successfully complete a tertiary calculus course.

The primary objective of this study is to investigate the difference in performance (if any) of Afrikaans first language students who attend Afrikaans lectures and Afrikaans first language students who attend English lectures. By factoring out some of the influence of the cultural background, previous exposure to mathematics education and the mathematical ability of the student (using a co-variate), a presumably fair comparison is drawn.

As secondary objectives, the following comparisons are made:

- the performances of all students who attend first language lectures with that of all students who attend second language lectures.

- the performances of all non-Afrikaans first language students (mainly African) who attend English second language lectures with that of all the Afrikaans first language students who attend English lectures. 


\subsection{Statistical procedures}

The statistical analysis focusses on different groups of students. The research participants are grouped according to their home languages and the language in which their first year university calculus lectures are presented. I examine the data by testing various comparative hypotheses on the adjusted average and observed average marks of the different groups.

I adjust first year university calculus marks (wherever possible) by factoring out the intellectual abilities as well as mathematical and social backgrounds of students (which are presumably contained within the grade twelve mathematics marks). This is done by the process of ANCOVA (analysis of co-variance), which relies heavily on the assumption of homogeneity (equal regression coefficients). Prior to ANCOVA, I test the hypotheses of homogeneity for the different groups represented in the various ANCOVA null hypotheses. If the assumption of homogeneity is violated, I revert to the analysis of observed secondary and first year tertiary mathematics marks by the process of ANOVA (analysis of variance). ANOVA merely compares the observed means of the various groups to determine whether there are at least two of them that differ significantly. I use a post hoc comparison test to identify differing means.

\subsection{Structure of the dissertation}

A comprehensive discussion on the background of South Africa with regards to language policy is presented in chapter 2. Some of the implications of recent changes in language policy are also reported in this chapter.

Chapter 3 covers the literature review. Reference is made to previous studies (mainly at primary and secondary school levels). Existing models for mathematics learning are investigated.

Chapter 4 discusses the research design. The model used in this study, is described. Special focus is placed on the sample and the assumptions about the sample (in particular with regard to the procedures implemented in the statistical analysis). Many of the opinions and findings expressed in the readings are reflected in the research design.

Chapter 5 reports on the statistical analysis. Various comparative tables are given on 
the sample and the hypothesis tests. The results of the hypothesis tests are stated formally and the results of the post hoc comparisons are also reported. A detailed discussion of the results is given.

Chapter 6 gives an overview of some of the shortcomings and limitations experienced in this study and provides some suggestions of improving on these. This chapter concludes with a discussion of some possible explanations and implications of the findings of this investigation and gives a précis of the results. 


\section{CHAPTER 2 \\ South African Background}

\subsection{Languages in South Africa}

The language of the former South African apartheid government, established in 1948, was predominantly Afrikaans - a language of Dutch origin, spoken mostly by white Afrikaners and the Cape Coloured communities. As a result, the majority of the universities of apartheid South Africa were Afrikaans medium institutions ensuring that white Afrikaans students would have easy access to university education presented in Afrikaans.

With the advent of democracy in 1994, it was decided to recognise 11 official languages. English is becoming the lingua franca by default - not by official policy. The other ten official languages are Afrikaans, Ndebele, Sepedi, Sesotho, Setswana, Swati, Tsonga, Venda, Xhosa and Zulu. With the exception of Afrikaans, all the other official languages are of African origin. The African languages do not have a subject language for science. As a result these students need to learn science (and especially advanced science) from an early age through a western language, English in particular.

The changes in language policies in South Africa forced the language issue at universities under the spotlight. Many of the traditionally Afrikaans medium universities (such as the University of Pretoria) now find the need to, at least partially, convert to English as a teaching medium. This is due, not only to the wider group of South Africans that have access to tertiary education since the dawn of democracy, but also due to the growing number of international students that enrol at these institutions as mentioned before.

\subsection{The South African population}

Although most official and public communication takes place in English, less than 10\% of South Africans are English first language speakers. The three most common home languages in South Africa (in descending order of numbers) are Zulu, Xhosa and Afrikaans. An indication of the proportional distribution of home languages of the South African 
population is given in Table 1. It is notable that this population is exceptionally heterogeneous.

TABLE 1: South Africa: Home language distribution (2001) ${ }^{40}$

\begin{tabular}{cc}
\hline Home language & \% of Population \\
\hline IsiZulu & 23.8 \\
IsiXhosa & 17.6 \\
Afrikaans & 13.3 \\
Sepedi & 9.4 \\
Setswana & 8.2 \\
English & 8.2 \\
Sesotho & 7.9 \\
Xitsonga & 4.4 \\
SiSwati & 2.7 \\
Tshivenda & 2.3 \\
IsiNdebele & 1.6 \\
Other & 0.5 \\
\hline
\end{tabular}

The heterogeneity of the group of English additional language (EAL) students (students for whom English is not their home language, but who speak English as a second or third language) adds to the linguistic difficulty of second language education. This is because students from different linguistic backgrounds may experience varying difficulty in coping with English instruction.

The numbers of students at South African tertiary institutions who are from African, Asian and Coloured communities have increased dramatically over the last ten years in general. Table 2 reports on the change in representation of various racial groups at the University of Pretoria since 1995. 
University of Pretoria etd - Gerber, A (2005)

TABLE 2: Student numbers of the University of Pretoria

\begin{tabular}{lccccc}
\hline & \% African & \% White & \% Asian & \% Coloured & Total \# Students \\
\hline 1995 & 16.36 & 81.49 & 1.24 & 0.91 & 25915 \\
1996 & 20.29 & 77.20 & 1.53 & 0.99 & 25960 \\
1997 & 21.99 & 74.97 & 2.10 & 0.95 & 26004 \\
1998 & 23.82 & 72.59 & 2.56 & 1.03 & 26684 \\
1999 & 24.11 & 71.64 & 3.24 & 1.01 & 26723 \\
2000 & 23.87 & 71.31 & 3.67 & 1.16 & 28093 \\
2001 & 25.66 & 68.92 & 4.08 & 1.35 & 30272 \\
2002 & 26.27 & 67.93 & 4.34 & 1.47 & 32163 \\
2003 & 28.09 & 65.69 & 4.75 & 1.47 & 34196 \\
\hline
\end{tabular}

From Table 2 it is evident that over the last nine years the number of African students at this institution have more than doubled from $25915 * 0.1636=4239$ to $34196 * 0.2809=$ 9605. The number of Asian students have increased by more than 500\% from 25915 * $0.0124=321$ to $34196 * 0.0475=1624$. The number of white students increased only by $6 \%$ from $25915 * 0.8149=21118$ to $34196 * 0.6569=22463$ and the percentage of white students is steadily decreasing. The drastic increase in the number of students from nonwhite cultures emphasises the need for investigations such as this study.

\subsection{The concern}

In an article in a prominent daily Afrikaans newspaper (Mboweni-Marais, 2003) on the performance of the grade twelve students of 2002, it is suggested that students who receive secondary level tuition in a language other than their mother tongue, are at a disadvantage. In a study of grade eight pupils' mathematics achievement, Howie (2003) finds that fluency

in English is a very significant factor in learning science and mathematics when tuition is in English. In reaction to these and similar reports, many prospective students and parents 
from the Afrikaans speaking community are dissatisfied with a shift in teaching medium from Afrikaans to English. These students had easy access to Afrikaans-medium tertiary education under the former regime and they believe that changing from Afrikaans-medium primary and secondary education to English-medium tertiary education will negatively impact on the their academic performance. This has been one of the factors motivating many of the former Afrikaans medium universities to now present - as far as practically possible - parallel lectures in English and Afrikaans. However, this casts an additional financial and logistic burden upon the university. On the other hand, not presenting lectures in both of these languages may cause these universities to lose students. Afrikaans students may be hesitant to enrol at a university where lectures are only presented in English. However, having Afrikaans as the only teaching medium is not politically justified.

Code switching (the teaching method by which the speaker switches between the first and the second language in a single session (Rollnick, 2000)) could possibly be a solution to the Afrikaans students' problem. However, in the context of the South African situation, code switching between Afrikaans and English will only address part of the problem, since there will probably also be students from language groups other than Afrikaans and English in class, who may not gain from a double medium lecture. Other drawbacks of code switching are that it slows lectures down and assumes exceptional bilingualism of the teacher.

Another possible solution might be the language approach to mathematics education suggested by Spanos et al (1988). They report in their study of Hispanic college students, that verbalisation exercises such as

- providing opportunities for students to create word problems;

- preparing students for and then asking essay-type questions in exams;

- using dialogue-journals with students, providing students with an opportunity to write about their mathematics problems, in a written dialogue between teacher and student

offer students the opportunity to acquire competence in both understanding and using mathematical language. However, this method could be too time consuming, making it a less attractive solution. 


\subsection{Motivation for this study}

Although the issue of second language education in South Africa goes far beyond that of only the Afrikaans speaking community, I focus my study on this group for various reasons. Firstly, this is the only group of second language learners where I could make use of a control group, (i.e. where there is data available on students attending first language lectures at the same institution). Not only can clearer conclusions be made with respect to Afrikaans first language learners, but by identifying specific areas of poor performance at a later stage, it can also shed new light on the groups of second language students where there are no control groups.

Secondly, the findings of this study will give more insight into the perceived disadvantage of Afrikaans students attending English classes compared to Afrikaans students attending Afrikaans classes. These insights may help South African universities and their governing bodies to decide on the policies concerning the language(s) in which lectures are presented. Should it be concluded that scaling down on Afrikaans lectures would not negatively impact students' performances, considerable financial and logistical gain could result.

In the majority of countries where English second language education is being researched, the EAL (English additional language) students are in a minority. In South Africa however, we have the uncommon situation that the EAL students form a big majority. This unique situation calls for special investigation. 


\section{CHAPTER 3}

\section{Literature Review}

\subsection{Introduction}

Much research has been conducted on the effect of second language teaching in elementary and secondary mathematics education (Adler, 1998; Cocking and Chipman, 1988; De Avila, 1988; Espinoza et al, 1975; Leap, 1988; Souviney, 1981). However, little research has been done in the field of second language teaching in tertiary mathematics. Barton and Neville-Barton's article (2003) on language issues of university students is one of the few studies published and I will discuss it in more detail in subsequent sections. Most of the literature cited in this review, however, refers to education at the lower educational levels.

Various factors that play a role in the successful completion of a mathematics course are discussed in the sections on models of mathematics learning and language in mathematics learning. In the latter section, I investigate the different languages involved in the learning of mathematics and explore their relevance with respect to each other. From the literature cited in these sections it seems as if the various languages used in the learning of mathematics can be categorised as either verbal (be it colloquial or mathematical) or written.

I proceed to focus on understanding the specific role of second language tuition in learning mathematics. I follow a line of reasoning by analysing the process of studying mathematics to arrive at a conceptual model to be used in the statistical analysis.

\subsection{Models of mathematics learning}

Various factors influence students' academic (and specifically mathematics) performance and it is essential to take careful consideration of these factors before embarking on a study that deals specifically with the issue of language.

According to Cocking and Chipman (1988) the three major categories of factors that 
have influence upon school learning are:

i) Entry characteristics of the learner

ii) Educational opportunities provided to the learner

iii) Motivation to learn

They specify entry characteristics to be cognitive ability patterns like being able to understand mathematical concepts, language skills, reading skills and learning ability. Educational opportunities might involve the time that students spend on their studies, the quality of their instruction, the appropriateness of the instruction language and additional parental or other assistance.

I list some of the specific factors cited in literature as influencing academic (and specifically mathematics) performance:

- $\quad$ home socio-economic status (Cocking and Chipman, 1988)

- $\quad$ parental encouragement and assistance (Cocking and Chipman, 1988; Tsang, 1988; Leap, 1998)

- $\quad$ interest (De Avila, 1988)

- $\quad$ career aspirations (MacCorquodale, 1988 )

- $\quad$ gender (MacCorquodale, 1988)

- $\quad$ culture (Leap, 1988; Rollnick, 2000; Saxe, 1988)

- $\quad$ language (De Avila, 1988; Lemke, 1990)

- $\quad$ general intelligence (Aiken, 1971; Feierabend, 1960; Wrigley, 1958)

- $\quad$ background in mathematics (Barton and Neville-Barton, 2003)

- $\quad$ teacher competencies (Cocking and Chipman, 1988)

- $\quad$ negative teacher attitudes towards students (Leap, 1988)

These factors do not necessarily belong to only one of the categories specified by Cocking and Chipman. For instance, a student's cultural background my cause him/her to be at a linguistic disadvantage at entry level whilst social customs within a culture may also 
influence a student's motivation to perform well in mathematics (as is the case with Indian Ute students in the USA and Canada (Leap, 1988)).

Not only do the factors not necessarily belong only to one category, but the individual factors are also not necessarily mutually exclusive. A student's low home socio-economic status may for instance be directly linked to the culture of the student or a student's interest in mathematics may motivate him/her to perform better in the subject.

The role of language in second language mathematics learning is complex in both of the above mentioned respects. Firstly, the influence that language has on mathematics learning refers to more than just the influence of the student's bilingualism. It also refers to (among others) the effectiveness of communication between the lecturer and the student, between the student and the written text and to the linguistic skills of the lecturer. Ultimately language may be categorised, for instance, as an entry characteristic and as an educational opportunity. Secondly, language and language ability cannot be viewed separately from factors like culture and general intelligence.

Difference in home language almost always implies difference in culture (Cocking and Chipman, 1988; MacCorquodale, 1988; Rollnick, 2000). Having to teach students from different cultural backgrounds in one classroom complicates the matter of second language learning even more since improving communication between two language groups also implies acquiring better understanding of the cultures involved. As a result teaching EAL students entails much more than merely bridging a language problem. Cocking and Chipman state, with respect to different cultural groups, that:

...all groups do not face the same problems and even if they do, the extent of ethnic diversity indicates that the same remedies may not be appropriate for all groups. (p. 42)

This is the case with Hispanic and Anglo college students in a study conducted by Mestre (1984) and quoted by Duran (1988). In his study, Mestre found that Hispanics experience the English language as a greater obstacle in solving mathematical questions than Anglo students do. O'Toole (1996) in his review of literature on the interface between science and language also reports the notion of student difficulties increasing with heterogeneity within the classroom:

...student difficulties do not seem to challenge teachers in relatively homogenous classes but when classes become more heterogenous, teachers look for help for themselves and their classes. (p.132) 
Complicating the matter of isolating a specific influential factor even more is the fact that the conclusions of different studies may seem somewhat contradictory, as is the case with De Avila (1980) and Mestre (1981). These studies are referred to by Cocking and Chipman (1988). In a study of grade 1, 3 and 5 Hispanic students, De Avila finds that language proficiency is not strongly predictive of mathematics achievement but Mestre reports significant positive correlation between problem solving skills and language proficiency of Hispanic college students. In the case of these two studies, the age of the students might be a significant factor, indicating once again that the influential factors are not always mutually exclusive and also that there may be some latent and uncontrolled yet influential variable.

In their model of influences on mathematics achievement, Myers and Milne (1988) differentiated between exogeneous (variables that originate externally or outside of the specific variables under investigation) and endogenous (intermediate) variables. Their model is specifically designed to study minority students within the United States. It is less general than that of Cocking and Chipman in the sense that the specific factors are already included in the model, but Myers and Milne recognise the intricate inter-relations of factors influencing mathematics performance. Various language measures, the mother's educational attainment, family income, years of residence in the United States, gender and the number of siblings make out the exogenous variables in the model. Endogenous variables are the student's home environment, English language proficiency, aspirations, types of mathematics courses taken and reading achievement.

Another element in the modelling of factors influencing mathematics learning that becomes evident from this model by Myers and Milne, is the setting-specific factors. In their model the number of years that a student has spent in the U.S.A. is considered to be a determining factor in mathematics achievement. In the case of South African students, there are other setting-specific factors that need to be taken into account. These are discussed in the section on the model implemented in this specific study (section 4.1).

All the different influences on mathematics achievement and their inter-relations make it difficult to isolate the role of language (and more precisely second language tuition) in 
mathematics learning. In the following section I focus on the specific role of language.

\subsection{Language in mathematics learning}

It could be supposed that because of the symbolism in mathematics, learning mathematics is independent of proficiency in the instruction language. However, there are researchers who state that this is in fact not true (Barton and Neville-Barton, 2003; Spanos et al, 1988).

Mathematics is not "language-free" and the particular vocabulary, syntax and discourse it presents challenges EAP learners [students attending an English for Academic Purposes course] especially, to develop their literacy in this discipline. (Barton and Neville-Barton, p.28)

Lemke (1990) makes it clear that mathematics in itself is not removed from language as such. In fact, he states that:

... mathematics itself, that is the use of mathematical expressions, is part of language, not something different from or alternative to language. (p.159)

Barton and Neville-Barton point out the complexity of the language issue, stating that:

There is a complex interaction between language features, context features, mathematical knowledge and use of symbols. (p. 27)

As discussed in the previous section, the influence of language in learning mathematics goes beyond that of the language of instruction.

In order to achieve the necessary in-depth mathematical understanding (or basic mental infrastructure as Thurston (1995) calls it), Thurston suggests that effective communication of mathematical ideas is the key. Language forms an integral part of this communication. McLean (2000) supports this in saying that

Many of the learning problems of students originate from an inadequate knowledge of the basic vocabulary.

There are many languages that play a part in the communication of mathematics (as will be discussed in section 3.3.3). In the following sections I discuss two main modes of communication, namely verbal mathematics and the written mathematics.

\subsubsection{Verbal mathematics communication}


Verbal mathematics communication could be subdivided into two main categories of language: Colloquial English and mathematical English.

Many researchers have recognised that these two languages, although both spoken in English, say, are indeed distinctly different. O’Toole (1996) acknowledges this:

There is a characteristically 'scientific' style of English. While its users consider the style to be a transparent vehicle for the discussion of material phenomena, the research ... suggests that it is translucent to those on the edges of the using communities and positively opaque to those outside. (p.113)

Rollnick (2000) also points out that the difference between conversational and scientific language is considerable:

...the difference between everyday language and science or mathematics terminology also leads to first language speakers learning a new language when learning science. (p.100)

With respect to the mathematical spoken English, Lemke (1990) says that the usage of language in mathematics deals with abstract generalisations and logical relationships and that

...the mastery of a specialized subject like science is in large part mastery of its specialized ways of using language. (p.21)

He explains that one can literally talk mathematics, either by reading the symbols or by converting the symbols into conventional words and phrases of the language of mathematical English. This statement puts the issue of symbolism and translation under the spotlight (discussed in section 3.3.3). The point that Lemke makes is that proficiency in conversational English is not the only prerequisite for English second language students to master mathematics. They also need to be familiar with scientific English.

In their study of primary school pupils in Papua New Guinea, Clements and Lean (1981) found that Papua New Guinea students handled word-free computational problems well, but that they had great difficulty with verbally presented arithmetic problems. In their interpretation of this result, they attribute the Papua New Guinea student's difficulty with verbal problems to their difficulty with English, and specifically with mathematical English. In another study of Papua New Guinea scholars, Clarkson (1991) attributes their poor performance in solving word problems to a lack of mathematical vocabulary. In these studies clear differentiation is made between the two types of English, i.e. colloquial and 
mathematical English and poor ability in mathematical English is identified to be a limiting factor in the mastering of mathematics. Barton and Neville-Barton (2003) also regard the mathematical English to be a more important factor than general English in the learning of university mathematics.

Spanos et al (1988) highlight the pitfalls of not specifically addressing the issue of learning the language of mathematics:

To expect students to "pick up" the language as they read the texts and listen to explanations in class is to court the kind of failure that too many students, both language minority and Englishspeaking, meet in their mathematics courses. (p.238)

With regard to mathematical English, Halliday (1975) suggests that this unique linguistic register of mathematics has special features that students of mathematics have to master. He defines this linguistic register as:

... a variety of language that is oriented to a particular context, to a certain type of activity, involving certain groups of people, with a certain rhetorical force. (p.5)

I illustrate these verbal colloquial and mathematical modes of mathematics communication by using the concepts of the numerator and denominator of a fraction.

When a teacher explains the concepts of the numerator and denominator to a student, he/she would use words like the top part or the bottom part of the fraction in order to give initial clarification of the concepts. Thereafter the mathematical terminology may be introduced, i.e. the terms numerator and denominator.

\subsubsection{Written mathematics communication}

The second mode of communication in mathematics is the written mathematics. Students need to learn to formalise mathematical concepts, using mathematical text and symbols. Cocking and Chipman (1988) refer to Spencer and Russell (1960), who claim that the difficulties in reading mathematics are due to the specialised language (symbols) used for expressing ratios, fractions and decimals. According to Brown (1994): 
For someone learning mathematics there is a similarity with learning a language in that there is a need to grapple with an inherited mode of symbolization and classification, arbitrarily associated with some pre-existing world. (p. 142)

When one considers that fluent reading and understanding of mathematical text and symbolism are the tools with which students access, learn and apply mathematical concepts and skills, the importance of proper mathematical literacy becomes even more evident (Bohlmann, 2001; Mestre, 1981; O’Toole, 1996).

Returning to our example of the fraction, the mathematically written format of the concept will be:

$$
\frac{a}{b} \text { or } a / b \text { or } a \div b \text { or even } a \times b^{-1}
$$

This example uses symbolism to communicate the mathematics in writing. Yet, written mathematics consists of various sub-languages which are used to communicate various genres of the written mathematics. These genres include proof, definitions and theorems (Marais, 2000; Lemke, 1990; Wheeler and Wheeler, 1979). In section 3.3.3 I explain some of the specific languages within the mode of written mathematics communication, which are utilised in the communication of these genres.

\subsubsection{Other classifications of languages in mathematics}

The classification of means of communicating mathematics discussed above is still broad. In order to understand the role of language in mathematics learning and the intricate interactions between all the various sub-languages, it is necessary to expand on the simple classification of three languages, i.e. colloquial English, mathematical English and written mathematics. Note however, that in the final model I only differentiate between the three main modes of communication.

I now refer to different points of view and classifications on the topic of classification of mathematics-languages.

Bohlmann (2001) discusses the various roles of language in the learning of mathematics: 
It [language] is the medium by which teachers introduce and convey concepts and procedures, through which texts are read and problems are solved. (p. 6)

There are many different languages involved in the learning of mathematics and used for the roles stated by Bohlmann. Careful consideration should be given to identifying these languages and determining their inter-relations, since in the end this will assist in locating the specific influence of second language instruction on mathematics learning. Various researchers (Lemke, 1990; Mestre, 1988) differentiate between the languages used in the learning of mathematics. All of these languages, or modes of communication, can be categorised as one of the following: Colloquial English, mathematical English or written mathematics. I have already addressed these three modes of mathematical communication.

Mestre (1988) identifies four types of language proficiency that can play a role in problem solving in a technical domain such as mathematics:

- proficiency with language in general

- proficiency in the technical language of the domain

- proficiency with the syntax and usage of language in the domain

- and proficiency with the symbolic language of the domain

He explains that general language proficiency relates to a student's reading speed and comprehension ability - especially with respect to written text. The technical language refers to the particular vocabulary and syntax used in mathematics that have equivalent counterparts in the naturally spoken English, but which can differ drastically from the colloquial English, depending on the context in which it is used. As an example, he uses the word product:

...in natural discourse a product is an item sold in a store, whereas in mathematics, product is the result of the operations of multiplication. (p.216)

Other words that differ in meaning in colloquial English and in mathematical English include rational, range and integrate (Dale and Cuevas, 1987).

Mestre explains the third language of syntax and language in the domain as the ability

to distinguish whether or not a word is being used mathematically and if so, how the various 
parts of the problem are mathematically related. The fourth language factor, symbolism, is specifically relevant to the domain of mathematics. Mestre explains that mathematical symbolism has a grammar of its own:

For example, the mathematical statement " $2<X<8$ " is totally "grammatical" within the symbolic language of mathematics; however, the variation " $2<X>8$ " is ambiguous since it states that $X>2$ and $X>8$, both of which cannot always be satisfied simultaneously. Further, the variation "2 $>X>8$ " is not grammatical since it implies that $X<2$ and $X>8$, either of which contradict the other. (p.216)

Wheeler and Wheeler (1979) also expand on the issue of mathematical symbolism and emphasise the importance of proficiency in symbolic language:

As in the study of any language, students of mathematics need only learn the symbols of the language, observe patterns in the usage of these symbols, and then use these patterns to express their own ideas and to develop their own applications... The ability to understand the basic patterns of the language of mathematics is the key to enjoying mathematics and using it effectively. (p.3)

Barton and Neville-Barton (2003) differentiate between five different forms of written mathematics: general English text, mathematical technical text, symbols, diagrams and graphs. They refer to Dale and Cuevas (1987), who describe the mathematics register in a particular language (e.g. English) in terms of unique vocabulary, syntax and discourse and differentiate between six vocabularies. They give examples of these vocabularies (as quoted from Barton and Neville-Barton):

- technical vocabulary, e.g. quadrilateral, algorithm, factorial;

- everyday vocabulary that takes on different meanings, e.g. rational, range, product, integrate;

- complex phrases combining more than one concept, e.g. least common multiple;

- several words signalling the same mathematical concept, e.g. add, sum, and, increase, plus;

- general English vocabulary;

- symbols (which can be both conventional and free, depending on context) e.g. ${ }^{+},=, p, x, y$.

(p.21)

With regard to the issue of translation, Lemke (1990) addresses the problem of students experiencing difficulty in switching between these three mathematical languages: 
Many students have trouble translating between mathematical symbols, mathematical English sentences, and ordinary English. (p.159)

Cocking and Chipman also refer to studies by Clement, Lochhead, and Monk (1981), Kaput and Clement (1979); Rosnick (1981) and Rosnick and Clement (1980). They all reported on the widespread inability of university engineering students to translate relationships expressed in colloquial language into corresponding mathematical expressions, and vice versa.

Clearly there are a variety of languages associated with mathematics and these languages inter-act with each other in a complex manner. It is necessary to keep these languages in mind when studying the specific influence of second language instruction on mathematics performance.

\subsection{Focussing on second language instruction}

Having to deal with a second language as instruction medium, can add to the problem of language, as McLean (2000) refers to it. In a citation of recent studies on second language learning in science, Rollnick (2000) rightly states that

$\ldots$ it is acknowledged that expecting students to learn a new and difficult subject through the medium of a second language is unreasonable, giving them a double task of mastering both science content and language. (p. 100)

This double task entails the acquisition of two conceptually difficult and different skills at once - one being related to language and the other to mathematics content (Bohlmann, 2001; Rollnick, 2000).

There are studies, such as the one by Mestre (1984) on Hispanic and Anglo students, indicating that EAL students at college level, within that particular setting, are indeed at a disadvantage. However, the study by Tsang (1988) shows that Asian-American EAL high school students do not necessarily perform worse in mathematics than their American counterparts do.

In their study of a sample of 83 students in total (54 of these were Asian EAL students), Barton and Neville-Barton (2003) found that EAL students are indeed at a disadvantage. They show that EAL students prefer mathematical symbols to express themselves as 
opposed to texts, diagrams or graphs. These students also understand the symbolic representations just as well or even better that the first language students do, but perform slightly worse than the first language students in symbolic questions. This shows that the EAL students' reliance on symbolism is not entirely grounded.

In their study of mathematics achievement of high school language minority students, Myers and Milne (1988) found that students from Italian/English, Chinese/English, French/English and German/English bilingual households perform significantly better than students from English monolingual households. However, students from Spanish/English bilingual and monolingual Spanish households perform significantly worse than English monolinguals do. These results are based on a maximum likelihood procedure, where the influence of background of the students on their mathematics performance is controlled. This study also illuminates the issue of how the influence of second language instruction on mathematics achievement differs from culture to culture (discussed in section 3.2).

\subsection{What is "proficient"?}

Having identified various different modes of mathematics communication, the basic question still remains: What level of proficiency in English is necessary to cope with mathematics when English is the medium of instruction?

According to Heugh (1999) the minimum vocabulary necessary to cope with English as instruction medium is 5000 words. She claims that after four years of home language instruction in primary school, accompanied by English as a subject, a student would have acquired only about 800 words. Barton and Neville-Barton (2003) suggest that even after six or more years of learning mathematics in an English-speaking environment, second language students will still be at a $10 \%$ disadvantage through lack of understanding of mathematical text.

In the case of English second language students in the South African schooling system, students get formal exposure to English from the first grade and they complete the English Second Language curriculum up to grade twelve. This has been the case even prior to 1994, when the new government took over. 
Besides this formal exposure to English, South Africans (especially those living in urban settings) also get exposure to English in daily life. It is the primary communication medium in both the printed and television media and the majority of official communication takes place in English. As a result, all South Africans need to be proficient in English - at least to some extent.

Is this partial proficiency sufficient to deal with English as an instruction medium in tertiary mathematics? Should this be the case, South Africans' bilingualism could be an advantage in their studies, enabling them to see different representations of a single idea (Rollnick, 2000; Bohlmann, 2001). Little research has been done on the exploitation of bilingualism for concept acquisition (Rollnick, 2000).

...the objects that are found in the mathematician's world, are generally distinguished by symbolic labels or names rather than colours. But those labels are as vivid as colours to those who inhabit that world. 


\section{CHAPTER 4}

\section{Research Design}

\subsection{Model implemented in this study}

From the preceding discussions it is clear that mathematics achievement relies on numerous variables. Besides the factors mentioned already, the specific setting of the research also needs to be taken into consideration when deciding on a model of influences on mathematics achievement.

In the South African case a model would, besides general factors like student intellectual ability and quality of education, ideally incorporate setting-specific factors concerning the political situation in the country at a specific stage in the student's career. Because of the political history of the country being such an important factor in the educational background of the student, the political background of the student could play a significant part. Maybe less setting-specific in terms of the South African context, but more so with university students in general, are factors concerning the sociological challenges students are facing at a specific time. As a result, the adaptability of a student to the university milieu could prove to be significant. For many students at the University of Pretoria, the largest residential university in South Africa, it is the first time that they leave home. They have to cope with the challenges of an unknown environment for the first time; they need to come to terms with an increased academic workload and adapt socially to this new and perhaps culturally different environment. All these elements add various settingspecific factors to the model.

Arriving at a model that incorporates all of the influential factors and takes into account all of their various interactions, could be quite a challenging task.

The proposed model is more of an on-going process than a definite, set structure. It is purely conceptual and will probably never be complete. However, I give a skeleton-diagram (Figure 1) of the model to give an indication of how the process starts.

In the proposed model, I classify the various influential factors under four fixed main 
categories:

i. Individual academic ability of the student

ii. External aids, currently at the student's disposal and assisting the student in successful completion of a mathematics course

iii. Various historical factors on the student's background (academically or otherwise);

iv. Personality traits of the student.

I subdivide these main categories into secondary categories and continue subdividing these categories (seemingly ad infinitum), until I end up (hypothetically speaking) with the individual factors. It is important to note that these categories are by no means independent of each other.

As an example, I expand on the category of external aids. External aids refers to support-mechanisms that the student currently have access to. In other words, these are factors, not belonging to the student's background, that support the student (for instance the standard of schooling he/she received). Some of these aids might be emotional support, some academic support. Thus I subdivide external aids into academic support systems and other means of support. Focussing only on the other means of support (this is not expanded on the diagram), one can subdivide it into, say, parental support, support from friends and fellow students and support from lecturers. Again only focussing on parental support, one could distinguish between the different types of actions parents can take to support the student and set up each of these as a new category. In this way, one will eventually end up with the specific elements of emotional support coming from the parents, which act as external aids to the student.

To illustrate the interaction between the various categories, I focus on the subcategory of other support. The extent to which emotional support acts as an external aid for the student, depends on the student's dependency upon emotional support, which is categorised under personality traits.

The influence of second language instruction could be categorised under lectures and 
FIGURE 1: Model implemented in this study

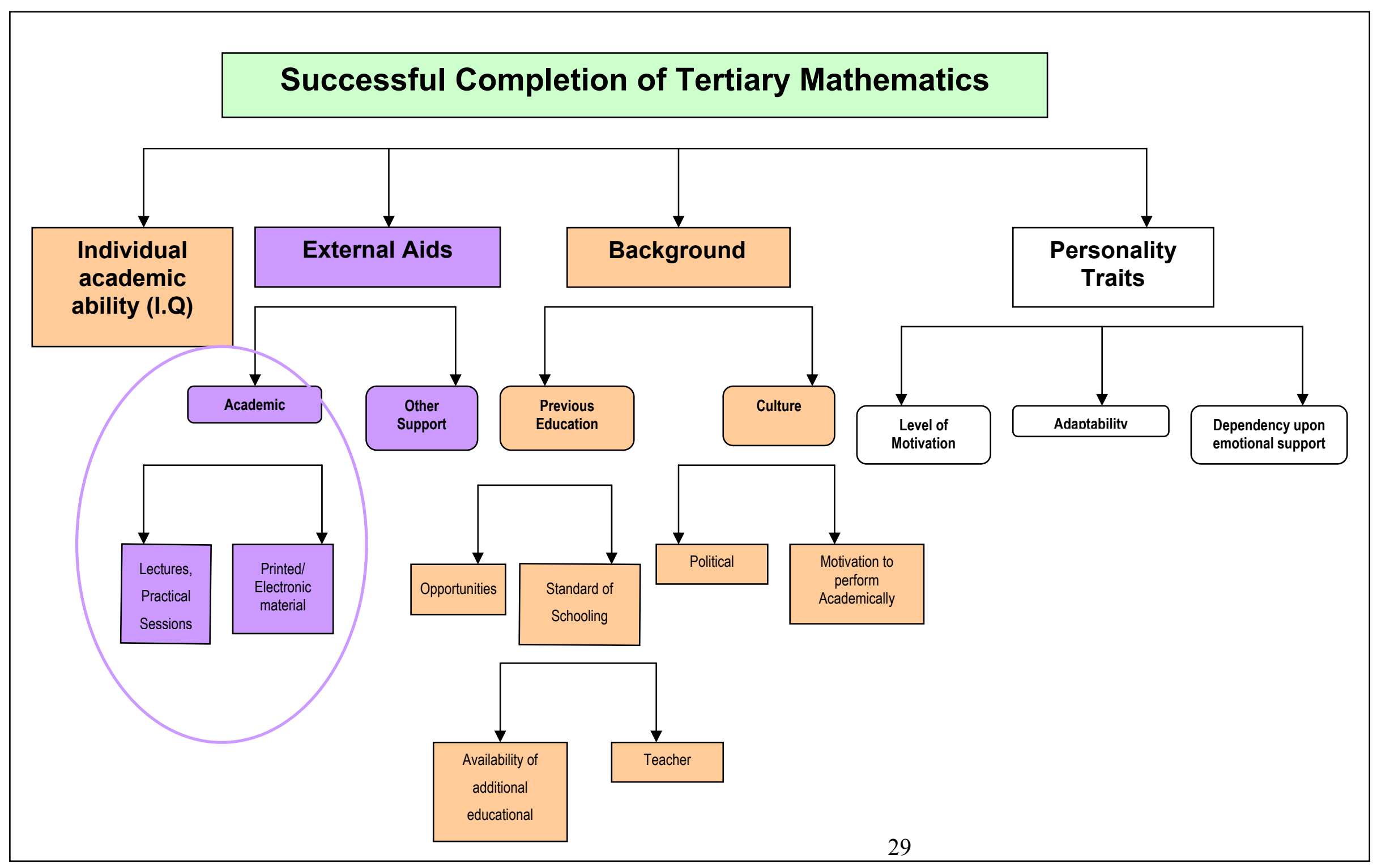


practical sessions, in the secondary category of academic support. Again there will be interactions with various other categories, the magnitude of which would be difficult to assess.

The colour scheme in the diagram is explanatory of what the statistical analysis (described in detail in chapter 5) presumably accomplishes. In short, I assume that information on the student's academic ability and background is contained within a variable called the co-variate. I also choose another variable, the dependent variable, which is assumed to contain all the information contained within the co-variate, but also information on the current external aids that the student can make use of. The influence of the information contained in the co-variate is then removed from the dependent variable via a procedure called the analysis of co-variance (ANCOVA) and the means of the resultant variable (called the adjusted means) are then compared for different samples.

\subsection{Linking the model to the research design}

Isolating the specific influence of the second language instruction medium on tertiary mathematics achievement is a daunting task, not only because it is one of numerous influential factors, but also because of the interaction between the various factors. In the proposed model, I classify the various factors as student intellectual ability, external aids, student background and personality traits of the student.

Ideally the statistical analysis will remove as much as possible of the influence of the factors that determine a student's mathematics achievement, until only the influence of second language instruction medium remains. I attempt to do this by literally separating the influences of some factors (using the analysis of co-variance or ANCOVA) from the dependent variable, by making use of an additional set of observations (co-variates) that contain information on these factors. Controlling the factor across the sample groups eliminates the influence of some of the other factors.

In the analysis I assume that the dependent variable contains information on the individual academic ability of the student, his/her background and the external aids in his/her studies. The co-variate contains information on the academic ability and background of the student. The adjusted variable resulting from the ANCOVA procedure will only 
contain information on the external aids. The influence of printed and electronic material (such as the prescribed textbook) is controlled, since all the students in the sample use the same study material - irrespective of their first language. I assume that we are left with the categories of the lectures and tutorials that the students attend, which in turn contain the influence of second language instruction.

There are a number of inconsistencies in the analysis that could not be controlled. These are described in chapter 6 , which gives a detailed description of the shortcomings in the study. Due to a lack of data the influence of these factors could not be accurately assessed. One of the major limitations in the link between the model and the analysis is the fact that this study is only quantitative. Since not all the influential factors are numerically quantifiable, many of the factors (especially those that can be categorised as personality traits) are not included in the analysis. These factors would probably be better assessed in a qualitative study.

\subsection{The data}

A grade twelve mathematics mark (Y) and a final first semester university calculus mark (X) are associated with each research participant. The grade twelve mark is the result of a student in the national examination of grade twelve students. The first year calculus mark is the average of a final examination and a semester mark (made up of the results for various class tests and projects) in a first year calculus course.

The grade twelve mathematics mark is the co-variate in the ANCOVA, containing information on the background (e.g. cultural and educational) and intellectual ability of the student. It could be argued that this variable also contains information on the personality traits of the student (e.g. level of academic motivation). However, this seems overpresumptuous.

The first semester university calculus mark is the dependent variable in the analysis. This variable is assumed to contain all the information that the co-variate does, but also information on current external support. 


\subsection{The sample}

The sample is a group of 836 engineering students collectively of 2002 and 2003 . For the analysis, the students are divided into four groups according to their home language and according to the language in which their formal lectures are presented. These groups are then compared with respect to their adjusted and observed means by way of hypothesis (significance) testing. The students within each group did not all attend the same weekly tutorial session, but the groups could not be sub-divided according to this variable as well, since this would have resulted in groups that are too small to achieve reliable statistical results.

A total of eleven students repeated the course; two of which are second language learners in group $\mathrm{B}_{2}$. The influence of this factor on the analysis is considered to be negligible.

The sample reflects the diversity of the South African population, with students from Afrikaans, English and various African communities. There are also some immigrant students (mainly Asian) included in the sample.

The abbreviations used in the reporting of the results are given in Table 3.

TABLE 3: Abbreviations for sample groups

\begin{tabular}{lc}
\hline Description & Abbreviation \\
\hline Afrikaans first language students attending Afrikaans (first language) lectures & $\mathrm{A}_{1}$ \\
Afrikaans first language students attending English (second language) lectures & $\mathrm{A}_{2}$ \\
English first language students attending English (first language) lectures & $\mathrm{E}_{1}$ \\
Other first language students attending English (second language) lectures & $\mathrm{B}_{2}$ \\
All students that attend first language lectures & $\mathrm{F}=\mathrm{A}_{1} \cup \mathrm{E}_{1}$ \\
All students that attend second language lectures & $\mathrm{S}=\mathrm{A}_{2} \cup \mathrm{B}_{2}$ \\
\hline
\end{tabular}

Group $\mathrm{A}_{2}$ consists mainly of students that have timetable clashes and a (small) number of Afrikaans first language students who prefer to attend the English lectures. The Afrikaans first language students who prefer to attend English lectures do so mainly for one of two reasons. Firstly, these students may feel that attending English lectures will prepare them for 
the English working environment they will have to operate within once their studies have been completed. Secondly, some of these students attended English secondary schools, so that it is actually easier for them to learn in English than it is to learn in Afrikaans.

Indian students are regarded as Group $\mathrm{E}_{1}$ research participants.

Group $\mathrm{B}_{2}$ consists mainly of African students. A few Asian students are also included in this group. The influence of the Asian students within this group is not investigated, since the appropriate data is not available.

Details on the composition of the sample with respect to group and year are reported in Table 4 and Table 5.

TABLE 4: Group sizes

\begin{tabular}{ccccccccccc}
\hline & \multicolumn{2}{c}{$\mathrm{A}_{1}$} & \multicolumn{2}{c}{$\mathrm{A}_{2}$} & \multicolumn{2}{c}{$\mathrm{E}_{1}$} & \multicolumn{2}{c}{$\mathrm{B}_{2}$} & \multicolumn{2}{c}{ Total } \\
\hline Year & 2002 & 2003 & 2002 & 2003 & 2002 & 2003 & 2002 & 2003 & 2002 & 2003 \\
$\mathrm{~N}$ & 129 & 337 & 3 & 25 & 40 & 125 & 41 & 136 & 213 & 623 \\
\hline
\end{tabular}

Roughly a quarter of the students in the sample are taken from the 2002 first year group and roughly half of the students in the total sample come from the population of Afrikaans first language students attending Afrikaans lectures $\left(A_{1}\right)$.

TABLE 5: Groups that constitute $B_{2}$

\begin{tabular}{ccc}
\hline & 2002 & 2003 \\
\hline African & 32 & 121 \\
Other (including Japanese, Chinese and French) & 9 & 15 \\
\hline
\end{tabular}

The vast majority of the students in group $\mathrm{B}_{2}$ are from the African community. The African students in the sample are mostly from the Zulu, Xhosa, Sotho, Tswana, Tshonga and Venda cultures. 
University of Pretoria etd - Gerber, A (2005)

other. But the symbols are no more that world than musical notation is music.

Ian Stewart 


\section{CHAPTER 5}

\section{Statistical Analysis}

\subsection{Linking the research design to the analysis}

In the research design, I identify two variables (a dependent variable and a co-variate) that are presumed to contain specific information. I elaborated on the nature of and assumptions about these variables in chapter 4. In this chapter I describe the statistical procedures that I implement to compare various group means.

ANCOVA, the procedure that is used to compare adjusted group means, assumes certain characteristics of the data with respect to homogeneity. I first test whether these characteristic traits are present in the data before performing the actual analysis. Since the assumption of homogeneity is not valid for all the data, I also perform analysis of variance (ANOVA), which does not make the assumptions about homogeneity that ANCOVA does. Doing the ANOVA analysis enables me to make additional group-wise comparisons. In this analysis however, I only compare the observed means (as opposed to the adjusted means as in the case of ANCOVA).

\subsection{The ANCOVA-assumption}

ANCOVA tests for difference in adjusted means and relies on the assumption that the datasets are homogeneous. This implies that for each of the groups being compared in the ANCOVA analysis, the slopes of the least squares linear fits on the scatter plot of $\mathrm{Y}$ vs. $\mathrm{X}$ have to be the same - statistically speaking. The validity of this assumption is tested and only in cases where the condition is met, the ANCOVA procedure is followed. In cases where this condition is not met, the results of the ANOVA tests are used to get some insight with respect to the particular groups.

In the test for homogeneity a null hypothesis of equal slopes is initially assumed for the various samples being compared. A test statistic (based on the regression coefficients of the observed sample) is computed and this statistic is used to make a decision as to whether the 
null hypothesis should be accepted or rejected. A level of significance, $\alpha$, is assumed for each hypothesis test. This quantity is the probability that the null-hypothesis is rejected if in actual fact it should be accepted. In a sense it is the probability that the inference that is made about the population from which the sample was drawn, is incorrect. This is sometimes called the type I error.

The regression coefficients of the observed data are given in Table 6.

TABLE 6: Regression coefficients (university calculus vs. grade twelve mathematics)

\begin{tabular}{cccccccc}
\hline & $\mathrm{A}_{1}$ & $\mathrm{~A}_{2}$ & $\mathrm{E}_{1}$ & $\mathrm{~B}_{2}$ & $\mathrm{~F}$ & $\mathrm{~S}$ & Total \\
\hline $\mathrm{b}$ & 0.561 & 0.39 & 0.496 & 0.58 & 0.527 & 0.385 & 0.511 \\
\hline
\end{tabular}

The p-value is the probability that the test statistic will be equal to or more extreme than the computed test statistic based on the observed data set, conditioned on the null hypothesis being true. This is also sometimes referred to as the exceedence probability. In my report on the hypothesis tests, I only give the p-values associated with each hypothesis test. This value should be interpreted as follows: If the p-value exceeds the $\alpha$-level, the nullhypothesis is not rejected; if the p-value is less than the $\alpha$-level, the null-hypothesis is rejected.

The null hypothesis of insignificant correlation is initially tested to determine whether the grade twelve mathematics marks and first year calculus marks correlate significantly. This test is equivalent to testing whether the regression coefficients given in Table 6 differ from zero. An $\alpha$-level of 0.05 is assumed.

TABLE 7: p-values for hypothesis tests for significant correlation

\begin{tabular}{ccccccc}
\hline & $\mathrm{A}_{1}$ & $\mathrm{~A}_{2}$ & $\mathrm{E}_{1}$ & $\mathrm{~B}_{2}$ & $\mathrm{~F}$ & $\mathrm{~S}$ \\
\hline $\mathrm{p}$ & 0 & 0.0013 & 0 & 0 & 0 & 0 \\
\hline
\end{tabular}


Since none of the p-values exceed 0.05, all sample groups exhibit significant correlation and as a result, the regression fits performed in Table 6 indicate statistically significant relation between $\mathrm{X}$ and $\mathrm{Y}$.

The first homogeneity-test is performed for all four sample groups simultaneously. The result of this test is a rejection of the null-hypothesis of equal regression coefficients (as can be seen from Table 8). This means that at least two of the observed regression coefficients in the comparison differ significantly and that ANCOVA cannot be done for all the groups simultaneously. As a second resort, I test the homogeneity of various combinations of data sets. The p-values obtained in the various tests for equal population regression coefficients are given in Table 8. An $\alpha$-level of 0.05 is implemented. Therefore, the null-hypothesis of equal regression coefficients is rejected if a p-value of less than 0.05 is obtained.

TABLE 8: p-values for hypothesis tests for equal regression coefficients

\begin{tabular}{c|cc|cc|cc}
\hline & $\mathrm{A}_{1}, \mathrm{~A}_{2}, \mathrm{E}_{1}, \mathrm{~B}_{2}$ & $\mathrm{~A}_{1}, \mathrm{~A}_{2}$ & $\mathrm{~A}_{2}, \mathrm{~B}_{2}$ & $\mathrm{~A}_{1}, \mathrm{E}_{1}$ & $\mathrm{~F}, \mathrm{~S}$ & $\mathrm{~F}, \mathrm{~B}_{2}$ \\
\hline $\mathrm{p}$ & 0 & 0.671 & 0.068 & 0.029 & 0.995 & 0 \\
\hline$\alpha=0.05$ & \multicolumn{6}{c}{}
\end{tabular}

The tests for equal regression coefficients reveal that due to non-homogeneity groups $\mathrm{F}$ and $\mathrm{B}_{2}$ and the two groups of first language learners cannot be compared. Consequently, ANCOVA can only be done for the two groups of Afrikaans first language learners, the two groups of second language learners and the combined groups of all first language students and all second language students.

\subsection{ANCOVA}

Since the assumption of homogeneity only holds true for three sets of comparisons $\left(\mathrm{A}_{1}\right.$ vs. $A_{2}, A_{2}$ vs. $B_{2}$ and $F$ vs. S) ANCOVA can only be done for these three comparisons. In the ANCOVA-procedure the effect of a co-variate is removed from the dependent variable in order to compare the adjusted means. The null-hypothesis of equal adjusted population means is assumed and it is evaluated using a test statistic. This test statistic is based on the adjusted sample means, which are reported in Table 9 for each of the three comparisons. It also reports on the p-values obtained in the ANCOVA analysis. The hypothesis tests for 
equal adjusted means are done at a significance level of 0.05 . The p-values that are obtained for the three comparisons are also given in Table 9.

TABLE 9: Observed and adjusted means and p-values in ANCOVA analysis

\begin{tabular}{crrrrrr}
\hline Group & $\mathrm{A}_{1}$ & $\mathrm{~A}_{2}$ & $\mathrm{~A}_{2}$ & $\mathrm{~B}_{2}$ & $\mathrm{~F}$ & $\mathrm{~S}$ \\
\hline Mean & 62.55 & 61.07 & 61.07 & 59.07 & 61.28 & 59.35 \\
Adj Mean & 62.75 & 57.73 & 60.68 & 59.56 & 61.02 & 60.17 \\
$\mathrm{p}$ & \multicolumn{2}{c}{0.018} & \multicolumn{2}{c}{0.361} & \multicolumn{2}{c}{0.494} \\
\hline
\end{tabular}

ANCOVA shows that there is indeed a significant difference in the performances of the two Afrikaans first language groups. This suggests that the Afrikaans first language students attending English lectures may be at a disadvantage, but note however that this conclusion is drawn on the basis that $\alpha=0.05$. Due to the fact that the p-value of 0.018 is still relatively high, the conclusion will be different if we use a lower $\alpha$-level of say $\alpha=0.01$. Therefore, although the analysis suggests that Afrikaans students perform better if they attend Afrikaans lectures, this result is by no means conclusive and more investigation needs to be done in this regard.

There is no significant difference in the adjusted mean performances of the entire group of first language learners and the entire group of second language learners.

ANCOVA also shows that there is no significant difference in the adjusted mean performances of the two groups of second language learners. This means that when the influence of the students' backgrounds and intellectual abilities is removed, the students from the Afrikaans community do not perform significantly different to students from the African community.

\subsection{ANOVA}

ANOVA is performed on the observed mean grade twelve mathematics $(\mathrm{Y})$ and calculus $(\mathrm{X})$ results respectively. The test assumes a null-hypothesis of equal population means and tests the assumption by means of a test statistic, which is based on the observed sample means. These observed means are reported in Table 10 for $\mathrm{X}$ and $\mathrm{Y}$ respectively. 
A significance level of 5\% is adopted in the ANOVA test. The p-values of the ANOVAtests are also given in Table 10.

TABLE 10: Observed means and p-values for ANOVA

\begin{tabular}{ccccc}
\hline & $\mathrm{A}_{1}$ & $\mathrm{~A}_{2}$ & $\mathrm{E}_{1}$ & $\mathrm{~B}_{2}$ \\
\hline Mean $(\mathrm{Y})$ & 72.794 & 77.107 & 71.479 & 69.847 \\
$\mathrm{p}=0.007$ & & & & \\
$\operatorname{Mean}(\mathrm{X})$ & 62.547 & 61.071 & 57.703 & 59.073 \\
$\mathrm{p}=0.001$ & & & & \\
\hline $\mathrm{F}(\alpha ; 3,832) \alpha=0.05$ & & & &
\end{tabular}

ANOVA shows that there are indeed at least two differing means in each of the two variables. The actual differing means are identified using a multiple comparison procedure (or post hoc comparison). The unrestricted least significant difference (LSD) test was implemented as the post hoc comparison test. The post hoc comparative tests are discussed in the following section.

\subsection{LSD multiple comparisons}

In a study by Saville (1990) he defines the inconsistency of a multiple comparison procedure:

A procedure is called inconsistent if for any two population means $\alpha_{1}$ and $\alpha_{2}$ the probability of judging them to be different depends on either the number of populations or the values of the sample means for the other populations. (p.177)

He finds the unrestricted LSD to be the only consistent multiple comparison procedure and thus I implement this procedure in the post hoc comparison.

Since these comparisons all relate to the same hypothesis test, the $\alpha$-level of the post hoc comparison tests should be adjusted in order to prevent an accumulation of the type I error. I implement the Bonferonni adjustment, which implies that in order to arrive at an $\alpha$ level of 0.05 the $\alpha$-level for the individual comparisons should be as follows: 


$$
\begin{aligned}
& \alpha=\frac{0.05}{\# \text { pairwise_comparisons }} \\
& =\frac{0.05}{6} \\
& =0.008
\end{aligned}
$$

As a result the LSD tests are done at $\alpha=0.008$ to account for the Bonferonni adjustment. The LSD comparisons assume a null-hypothesis of equal means and base the test statistic on observed difference in means. The observed means are reported in Table 10. The pvalues of the individual comparisons are given in Table 11.

TABLE 11: p-values for LSD

\begin{tabular}{ccccccc}
\hline & $\mathrm{A}_{1}, \mathrm{~A}_{2}$ & $\mathrm{~A}_{1}, \mathrm{E}_{1}$ & $\mathrm{~A}_{1}, \mathrm{~B}_{2}$ & $\mathrm{~A}_{2}, \mathrm{E}_{1}$ & $\mathrm{~A}_{2}, \mathrm{~B}_{2}$ & $\mathrm{E}_{1}, \mathrm{~B}_{2}$ \\
\hline $\mathrm{Y}: \mathrm{p}$ & 0 & 0.058 & 0 & 0 & 0 & 0.105 \\
$\mathrm{X}: \mathrm{p}$ & 0.306 & 0 & 0 & 0.031 & 0.117 & 0.195 \\
\hline
\end{tabular}

$\mathrm{F}(\alpha ; 3,832) \alpha=0.008$

Group $A_{2}$ does not differ significantly from $A_{1}, E_{1}$ or $B_{2}$ students in their tertiary calculus achievement. However, at school level mathematics $\mathrm{A}_{2}$ students perform significantly better than all of these groups, indicating that $\mathrm{A}_{2}$ students might indeed be at a disadvantage due to second language instruction.

\subsection{Discussion}

The significance level associated with the ANCOVA tests is 5\%. ANCOVA indicates that there is a significant difference in performances of $\mathrm{A}_{1}$ and $\mathrm{A}_{2}$ students. However, had a significance level of $1 \%$ been implemented, the hypothesis of equal adjusted means would not have been rejected $(\mathrm{p}=0.018)$. Therefore, although this test shows that these two groups differ, the statistical result is not very convincing. Alternative tests and more investigative studies are needed to confirm this result. As a second resort, I do ANOVA tests on the data as well. These are discussed later in this section.

There seems to be no significant difference when the entire group of second language learners $(\mathrm{S})$ is compared with the entire group of first language students $(\mathrm{F})$. This result 
seems to contradict the one of difference in performance of $A_{1}$ and $A_{2}$ students. However with regards to the composition of $S$, the size of group $B_{2}$ is considerably greater than that of group $A_{2}$, so that the overall figure is in actual fact more representative of $B_{2}$ students than it is of $A_{2}$ students. The reason for this seemingly contradictory result is sought in the ANOVA analysis. In fact, the result of the ANOVA comparison of $\mathrm{B}_{2}$ and $\mathrm{E}_{1}$ indicates that these two groups do not differ significantly, which may explain this ANCOVA result. In general, the ANCOVA result of insignificant difference in the performances of groups $\mathrm{F}$ and $\mathrm{S}$ again supports the idea that in fact proficiency in mathematical English and written mathematics is more predictive of mathematics achievement than proficiency in the everyday English. This result supports that of De Avila (1980) who concludes that language proficiency of Hispanics is not strongly predictive of mathematics achievement. It also supports the conclusion of Barton and Neville-Barton (2003) that ability in mathematical English is more important than ability in colloquial English.

ANCOVA also reveals that there is no significant difference in the performances of groups $A_{2}$ and $B_{2}$. This result suggests that, with regards to second language instruction medium, neither of the two groups of second language students is disadvantaged more than the other. This may be somewhat surprising, since all $\mathrm{B}_{2}$ students have been exposed to second language instruction since secondary school and many of the $\mathrm{A}_{2}$ students only receive English tuition for the first time at university level. A possible explanation for this result may be that Afrikaans students' proficiency in English (and indeed mathematical English) is adequate for successful completion of a first year university calculus course. It might also support the notion that proficiency in written mathematical communication contributes greatly to success in mathematics. Another explanation for this result might be that due to the amount of exposure that South Africans get to English in everyday life, Afrikaans students' understanding of English (even if they attend Afrikaans medium schools) is at least as good as that of African students (who mainly attend English medium secondary schools).

The ANOVA tests are not as strong as the ANCOVA tests in that these procedures do not take into account the influence of a co-variate. Still, I perform ANOVA tests on both the dependent variable and the co-variate and combine the results of the two ANOVA tests in 
my interpretation. It is important to note that because of this combined interpretation of the ANOVA hypothesis test results, each with a significance level of $5 \%$, the following conclusions are based on a significance level of only $10 \%$.

The ANOVA investigation reveals that on a 5\% significance level, there is no difference in the average performance in first year calculus of $A_{1}$ and $A_{2}$ students. However, these groups seem to differ significantly in their mean school mathematics achievement, in that the $A_{2}$ students are actually stronger in secondary mathematics than $A_{1}$ students. Therefore the $A_{2}$ students actually outperformed the $A_{1}$ students on first year university calculus level and the decline in performance of $\mathrm{A}_{2}$ students in tertiary calculus might actually be due to a lack of proficiency in the second language instruction medium. This result supports that of Mestre (1981) who reports significant positive correlation between problem solving and language proficiency of Hispanic college students. Note that there are many extraneous influences that have not been accounted for, such as factors regarding the lecturer and tutor, which may also explain this result.

The performances of $A_{1}$ and $E_{1}$ students in school mathematics do not differ significantly, but at tertiary level $A_{1}$ students seem to do significantly better than $E_{1}$ students. This may be the result of some uncontrolled extraneous variable, which only come into play at the university level of mathematics. The fact that most of the lecturers who teach in English themselves are in actual fact Afrikaans first language speakers, might explain this result.

There is a difference in the performances of $A_{1}$ and $B_{2}$ students at secondary mathematics level. This difference is maintained in their first year university calculus performances. This conservation of difference in performance is to be expected, since both these groups are exposed to the same instruction-medium at both levels of mathematics.

Although students in group $\mathrm{A}_{2}$ perform significantly better in high school mathematics than the $E_{1}$ students do, there is no significant difference in their tertiary calculus achievements. Thus, in actual fact the $\mathrm{A}_{2}$ students perform worse than the $\mathrm{E}_{1}$ students do at tertiary calculus level. This could again support the notion that the $\mathrm{A}_{2}$ students are at a disadvantage since, although they seem to be the better performers of the two groups of 
students, their calculus achievement at tertiary level do not differ significantly from that of the $\mathrm{E}_{1}$ students. Again there may be some other extraneous variable, which is not accounted for in the analysis, which may have caused this result.

In their comparison of EAL (mainly Asian) and English first language students Barton and Neville-Barton (2003) also found the (Asian) EAL students' performance to be worse than that of the first language students. Barton and Neville-Barton's inference is purely made by comparing observed average achievements and no significance testing is done. Although this study supports their finding, there is still no certainty as to whether it is actually their supposed lower level of English language proficiency that cause Afrikaans first language students to perform worse.

$A_{2}$ students seem to perform better at school level mathematics than the $B_{2}$ students do. However, at tertiary level, the two groups do not differ significantly. This could either be due to poorer achievement of $\mathrm{A}_{2}$ students or an improvement in achievement by the $\mathrm{B}_{2}$ students. The result of the pair-wise comparison between $\mathrm{A}_{2}$ and $\mathrm{E}_{1}$ indicates a decrease in the performance of the $A_{2}$ students relative to that of the $E_{1}$ students so that I would favour the explanation that a decrease in $\mathrm{A}_{2}$ achievement accounts for the result of the comparison made between $A_{2}$ and $B_{2}$. Note that in the ANCOVA-tests these two groups do not differ significantly with respect to their adjusted means. Since the ANCOVA-results are stronger and implement a significance level of 5\%, I would ultimately favour a conclusion of no significant difference. However, I strongly suggest that further investigation should be done with respect to these two groups.

There is no significant difference in the performances of $E_{1}$ students and $B_{2}$ students either with respect to secondary or tertiary mathematics. Again the result of the school mathematics comparison is maintained in the university calculus comparison. This result is to be expected, since both of these groups are exposed to the same instruction language at both educational levels.

To conclude, when $\mathrm{A}_{2}$ students are compared with cultural peers in the South African context $\left(A_{1}\right.$ and $\left.E_{1}\right)$, they perform significantly worse; when $A_{2}$ students are compared to 
African students, there seems to be no significant difference in performance. The comparison of the entire group of second language students and the entire group of first language students in South Africa indicates that there is no significant difference; however, it is important to keep in mind that there is still a lot of inherent variability in these two groups. 


\section{CHAPTER 6}

\section{Conclusion}

\subsection{Limitations of the study}

The shortcomings in the choice of the sample group and in the analysis are discussed. Increasing the sample sizes (especially in the case of group $\mathrm{A}_{2}$ ) and controlling all extraneous variables (like tutor sessions that students attend) should address many of the limitations mentioned in this section. Forcing the sample size of $\mathrm{A}_{2}$ to be bigger would however mean forcing students to attend second language lectures, which would be unfair towards these students. Shortcomings in the analysis are primarily due to the shortage of data, bias and inconsistencies in analysis procedures and certain characteristics (e.g. nonhomogeneity) of the data that prohibit the usage of certain statistical procedures. I list the shortcomings and suggest methods of improving on them.

- Some of the students who attend second language formal lectures had the opportunity to attend first language tutorials. The effect of this source of variance cannot be assessed, due to a lack of data and this is one of the first causes of inconsistency in the analysis. The influence of this factor could be controlled by, for instance, forcing students to attend second language tutorials, but that would again seem unfair.

- Group $\mathrm{A}_{2}$ may not be representative of the population of Afrikaans students, since these students could be the academically stronger students (especially referring to their grade twelve mathematics marks). Taking a larger sample of $\mathrm{A}_{2}$ students from a variety of school backgrounds will improve the sample-representation of the population of Afrikaans first language students.

- $\mathrm{A}_{2}$ students in this sample may be more proficient in English than the majority of the Afrikaans student population since some of these students come from English secondary schools. This factor is not assessed due to the absence of such data. Specifically including students from Afrikaans schools in this sample group will resolve this issue.

- The influence of using different lecturers (either for the formal lectures or the tutorials) 
can also be a source of inconsistency. Four lecturers and a number of tutors (data on the actual number were not available) were involved in this study. This category of influential factors could not be controlled in this study, since just using students from a specific formal lecturer and tutor would have caused the sample to be too small.

- The English lectures are mostly presented by non-English first language speakers. Although these lecturers are proficient in English, this may be a cause for some bias in the study. Currently there is not enough data on the performance of students attending English lectures presented by English first language lecturers at the University of Pretoria.

- Indian students are regarded as English first language students. Data on the number of Indian students were not available, and as such I cannot determine the influence of these students.

- The non-homogeneity of the data does not allow for all the adjusted mean comparisons originally planned for the study. More and bigger samples may solve this problem and might perhaps give more conclusive results - especially if one considers the small sample size of group $\mathrm{A}_{2}$.

- The assumption that each of the groups is relatively homogeneous (or that the co-variate removes diversity within each of the sample groups in the ANCOVA-procedure) is risky. Controlling more of the extraneous variables (e.g. lecturer, tutorial) within each of the groups will contribute to the homogeneity.

- Referring to the proposed model, the influence of factors belonging to the category of personality traits of the students and of external means of support outside the category of academics, were not taken into account. This is mainly because of the fact that numeric data on this type of information is not available. To properly investigate the influence of factors in these categories on student's mathematics achievement, one would probably have to revert to qualitative research. 
- Ideally the samples across the groups should also be as homogeneous as possible (especially with regards to factors not contained within the co-variate) except of course for the variables under investigation, i.e. language of instruction and home language.

- Although students over all groups make use of the same study material, there are still variables that are unaccounted for (e.g. residential arrangements of the student, age). Ideally as many of these variables as possible should be controlled.

Although these factors may have influenced the results of this study, I am of the opinion that conclusions of this study will contribute to understanding the influence that second language teaching in South Africa has on student performance. I included as many of the influential factors as possible in the investigation, without allowing the analysis to get too involved. Since this is an initial study meant only to give early indications of what the influence of second language instruction is on Afrikaans first language students, I was forced to use what data was available. However, various influential variables (e.g. school background, tutor sessions attended) were identified and will be included in future studies.

More research needs to be done not only with respect to the Afrikaans first language group, but also with respect to all the other ethnic groups in South Africa.

\subsection{Conclusion}

What is the extent of the linguistic disadvantage of South African second language students? I focussed my study on Afrikaans first language students and performed various statistical techniques on secondary and tertiary mathematics results. Also, some insight is gained on the performance of African second language students.

There seems to be a statistically significant difference in the performances of the Afrikaans students attending Afrikaans lectures and Afrikaans students attending English lectures. This conclusion is based on the results of two statistical analyses. It seems that although the Afrikaans students that attend English lectures are academically stronger than 
the Afrikaans first language students that attend Afrikaans lectures, there is no difference in performance between the two groups. This supports the findings of Barton and NevilleBarton (2003) and Mestre (1981) that second language students are at a disadvantage to first language students. It is suggested however that more investigation be done before making definite conclusions with respect to these two groups.

Should it be found that the two groups of Afrikaans first language students differ significantly, it might be advisable to continue with parallel Afrikaans and English lectures especially in the case of undergraduate courses where the student numbers of Afrikaans first language students justify the additional sessions. However, should it be found that there is no significant difference in the first year university calculus achievement of Afrikaans students attending Afrikaans lectures and Afrikaans students attending English lectures, presenting lectures only in English becomes a more attractive option. In doing so, universities could save on financial expenses and it could lighten the logistical burden considerably.

There is no notable difference in the performance of the group of all students attending first language lectures (Afrikaans and English) and the group attending second language lectures (Afrikaans and African students attending English lectures). This result is reasonable, since South African scholars get a considerable amount of formal training in English. South Africans are also increasingly exposed to English in everyday life, where they are often required to interact both formally and informally in English. This result suggests that students attending English second language lectures in South Africa have an adequate understanding of English (be it general conversational English or mathematical English), especially in the case of African EAL students. It may also suggest that proficiency in the language of instruction does not have as big an influence on performance in tertiary calculus as proficiency in written or verbal mathematics might have. Indeed, the findings of the study conducted by Clements and Lean (1981) indicate that students handle word-free (e.g. symbolic, graphical) questions with more ease than they do verbally presented arithmetic problems. Also, Clarkson (1991) attributes the poor performance of Papua New Guinea scholars to poor mathematical vocabulary. 
There is no difference in the performances of the two groups of second language learners (Afrikaans and other - mainly African). This result was based on two relatively small

samples (compare the sample size of the group of Africans with that of the group of Afrikaans students attending Afrikaans lectures). However, it suggests that none of these two groups are more likely to be disadvantaged by second language instruction in first year tertiary calculus when intellectual ability and mathematics background are taken into account. This finding also supports the notion that proficiency in everyday English may not be as much of a prerequisite for mathematics achievement as proficiency in mathematical English and written mathematics may be. In their study of the achievements of university mathematics students, Barton and Neville-Barton (2003) regard proficiency in mathematical English as an important factor. Their conclusion is supported by the result of this analysis. 


\section{Bibliography}

1. Adler J. (1998). A language of teaching dilemmas: Unlocking the complex multilingual secondary mathematics classroom. For the learning of mathematics, 18(1), 24-33.

2. Aiken L. (1971). Verbal factors and mathematics learning: A review of research. Journal for research in mathematics education, 2, 304-313.

3. Barton B. \& Neville-Barton P. (2003). Language issues in undergraduate mathematics: a report of two studies. New Zealand journal of mathematics (supplement), 32, 19-28.

4. Bohlmann C. (2001). Reading skills and mathematics. Communications: Third southern hemisphere symposium on undergraduate mathematics teaching, 5-14.

5. Brown T. (1994). Towards a hermeneutical understanding of mathematics and mathematical learning. In Ernest P. (Ed.), Studies in mathematics education. London: The Falmer Press, 141-150.

6. Clarkson P.C. (1991). Mathematics in a multilingual society. In Durkin K. \& Shire B. (Ed.), Language in mathematical education: Research and practice. Buckingham: Open University Press, 235-246.

7. Clement J., Lochhead J. \& Monk G. (1981). Translation difficulties in learning mathematics. American mathematical monthly, 4, 286-290.

8. Clements M.A. \& Lean G.A. (1981). Influences on mathematics learning in community schools in Papua New Guinea: Some cross-cultural perspectives. Mathematics education center report, 13, Papua New Guinea university of technology.

9. Cocking R.R. \& Chipman S. (1988). Math achievement of language minorities. In Cocking R.R. \& Mestre J.P. (Ed.), Linguistic and cultural influences on learning mathematics. Hillsdale, New Jersey: Lawrence Erlbaum Associates, Inc., 17-46. 
10. Dale T.C. \& Cuevas G.C. (1987). ESL through content-area instruction. In Crandall J. (Ed.), Integrating language and mathematics learning, Engelwood Cliffs, New Jersey: Prentice Hall Regents, 9-52.

11. De Avila E. (1980). Relative language proficiency types: A comparison of prevalence, achievement level, and socioeconomic status. Report submitted to the RAND Corporation.

12. De Avila E.A. (1988). Bilingualism, cognitive function, and language minority group membership. In Cocking R.R. \& Mestre J.P. (Ed.), Linguistic and cultural influences on learning mathematics. Hillsdale, New Jersey: Lawrence Erlbaum Associates, Inc., 101121.

13. Duran R.P. (1988). Bilinguals' logical reasoning aptitude: A construct validity study. In Cocking R.R. \& Mestre J.P. (Ed.), Linguistic and cultural influences on learning mathematics. Hillsdale, New Jersey: Lawrence Erlbaum Associates, Inc., 241-258.

14. Espinoza R.W., Fernandez C. \& Dornbusch S.M. (1975). Factors affecting Chicano effort and achievement in high school. Astibos: Journal of Chicano research, 1, 9-30.

15. Feierabend R. (1960). Review of research on psychological problems in mathematics education. In Research problems in mathematics education, Monograph \#3. U.S office of education, 3-46.

16. Halliday M.A.K. (1975). Some aspects of sociolinguistics. In Jacobson E. (Ed.), Interactions between linguistics and mathematics education, 64-73. Final report of the symposium sponsored by UNESCO, CEDO and IMCI, Nairobi, Kenya, September 111, 1974. (UNESCO Report no. Ed-74/CONF. 808. Paris: UNESCO, 67-73.)

17. Heugh K. (1999). Languages, development and reconstructing education in South 
Africa. International journal of educational development, 19, 301-313.

18. Howie S. (2003). Success at maths, science depends on English skills, study finds. Sunday Independent, 1 June 2003.

19. Kaput J. \& Clement J. (1979). Letter to the editor. The journal of children's mathematical behavior, 2(2), 208.

20. Leap W.L. (1988). Assumptions and strategies guiding mathematics problem solving by Ute Indian students. In Cocking R.R. \& Mestre J.P. (Ed.), Linguistic and cultural influences on learning mathematics. Hillsdale, New Jersey: Lawrence Erlbaum Associates, Inc., 161-186.

21. Lemke J.L. (1990). Talking science: language, learning and value. Norwood, New Jersey: Ablex Publishing Corporation.

22. MacCorquodale P. (1988). Mexican-American women and mathematics: Participation, aspirations, and achievement. In Cocking R.R. \& Mestre J.P. (Ed.), Linguistic and cultural influences on learning mathematics. Hillsdale, New Jersey: Lawrence Erlbaum Associates, Inc., 137-160.

23. Marais C. (2000). Comparing first years' reasoning styles in formal logic and other mathematical contexts. Dissertation submitted for Master of Science, Mathematics institute, University of Warwick.

24. Mboweni-Marais K. (2003). Moedertaal vuurpyl vir uitmunt in 'pynvakke'. Beeld, 26 June 2003, 15.

25. McLean A. (2000). The predictive approach to teaching statistics, Journal of statistics education, 8(3). Retrieved on 28/05/2004 from www.amstat.org/publications/jse/secure/v8n3/mclean.cfm

26. Mestre J. (1984). On the relationship between the language of natural discourse and the 
language of logic: The interpretation of semantically complex sentence. Amherst, MA: University of Massachusetts, Cognitive processes research group. (ERIC document reproduction service no. ED 268 819)

27. Mestre J.P. (1981). Predicting academic achievement among bilingual Hispanic college technical students. Educational and psychological measurement, 41, 1255-1264.

28. Mestre J.P. (1988). Language comprehension and problem solving. In Cocking R.R. \& Mestre J.P. (Ed.), Linguistic and cultural influences on learning mathematics. Hillsdale, New Jersey: Lawrence Erlbaum Associates, Inc., 221-240.

29. Myers E. \& Milne A.M. (1988). Effects of home language and primary language on mathematics achievement: A model and results for secondary analysis. In Cocking R.R. \& Mestre J.P. (Ed.), Linguistic and cultural influences on learning mathematics. Hillsdale, New Jersey: Lawrence Erlbaum Associates, Inc., 137-160.

30. O'Toole M. (1996). Science, schools, children and books: Exploring the classroom interface between science and language. Studies in science education, 28, 113-143.

31. Richards P. (1982). Difficulties in learning mathematics. In Cornelius M. (Ed.), Teaching mathematics. London: Nichols Publishing Company, 59-133.

32. Rollnick M. (2000). Current issues and perspectives on second language learning of science. Studies in science education, 35, 93-121.

33. Rosnick P. (1981). Some misconceptions concerning the concept of variable. The mathematics teacher, $\mathbf{7 4}, 418-420$.

34. Rosnick P. \& Clement J. (1980). Learning without understanding: The effect of tutoring strategies on algebra misconceptions. Journal of mathematical behavior, 3, 3-27.

35. Saville D.J. (1990). Multiple comparison procedures: The practical solution. The 
American statistician, 44 (2), 174-180.

36. Saxe G.B. (1988). Linking language with mathematics achievement. In Cocking R.R. \& Mestre J.P. (Ed.), Linguistic and cultural influences on learning mathematics. Hillsdale, New Jersey: Lawrence Erlbaum Associates, Inc., 47-62.

37. Souviney R. (1981). Teaching and learning mathematics in the community schools of Papua New Guinea. The indigenous mathematics project, working paper 20.

38. Spanos G., Rhodes N.C., Dale T.C. \& Crandal J. (1988). Linguistic features of mathematical problem solving: Insights and applications. In Cocking R.R. \& Mestre J.P. (Ed.), Linguistic and cultural influences on learning mathematics. Hillsdale, New Jersey: Lawrence Erlbaum Associates, Inc., 221-240.

39. Spencer P.L. \& Russell D. (1960). Reading in arithmetic. In Grossnickle F.E. (Ed.), Instruction in arithmetic. Twenty-fifth yearbook of the National council of teachers of mathematics. Washington, DC: NCTM, 202-223.

40. Statistics South Africa (2003). Census 2001: Key results. Retrieved on 03/02/2004 from http://www.gov.za/reports/2003/census01_key.pdf.

41. Thurston W.P. (1995). On proof and progress in mathematics. For the learning of mathematics, 15, 29-37.

42. Tsang S. (1988). The mathematics achievement characteristics of Asian-American students. In Cocking R.R. \& Mestre J.P. (Ed.), Linguistic and cultural influences on learning mathematics. Hillsdale, New Jersey: Lawrence Erlbaum Associates, Inc., 123136.

43. Wheeler R.E. \& Wheeler E.R. (1979). Mathematics: An everyday language. John Wiley \& Sons Inc., 3 .

44. Wrigley F. (1958). Factorial nature of ability in elementary mathematics. British 
University of Pretoria etd - Gerber, A (2005)

journal of educational psychology, 28, 61-78. 